\title{
Intra-abdominal Ruptured Liver Abscess: Computed Tomography and Clinical Features
}

Huynh Quang Huy ${ }^{1 *}$, Le Cong Tri ${ }^{2}$, Le Quang Minh ${ }^{3}$ and Nguyen Quoc Vinh ${ }^{4}$

*Correspondence: huyhq@pnt.edu.vn

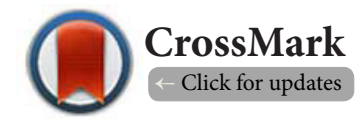

'Radiology Department, Pham Ngoc Thach University of Medicine and HCMC Oncology Hospital, Vietnam.

${ }^{2}$ Surgery Department, Cho Ray hospital, Vietnam.

${ }^{3}$ Department of Health, Ministry of Public Security, Vietnam.

${ }^{4}$ General Surgery Department, HCMC Medical and Pharmacy University Hospital, Vietnam.

\begin{abstract}
Objectives: The purpose of this study is to describe the computed tomography (CT) and clinical findings of intraabdominal ruptured liver abscess.

Patients and Methods: The CT and clinical findings of 32 patients who had a confirmed intra-abdominal ruptured liver abscess were analyzed retrospectively at Cho Ray hospital between 2014 and 2018.

Results: 32 patients with a median age of $53.3 \pm 15.3$ years (range, $24-85$ years). There were more men than women in the study, with a male-to-female ratio of 1.9:1. Most of the patients were suffering from abdominal pain (96.9\%), malaise and anorexia (96.9\%), fever (78.1\%), peritonitis (78.1\%). The mean size of the liver abscess was $8.4 \mathrm{~cm}$ (range, $4.0-14 \mathrm{~cm})$. A single abscess was found in 11 patients, and multiple abscesses were seen in 21 patients. Unilobar involvement was seen in 29 patients, with the right lobe affected more commonly (68.8\%, 22 of 32). The abscesses were completely liquefied in 25 patients and gas in the abscess cavity in 7 patients. Free intraperitoneal fluid was seen in all patients.

Conclusion: A knowledge of intra-abdominal ruptured liver abscess is important for an early diagnosis and appropriate management.
\end{abstract}

Keywords: Liver abscess, ruptured, computed tomography, clinical

\section{Introduction}

Liver abscess is a common condition in tropical countries and is associated with significant morbidity and mortality. Traditionally, there are two major classifications of hepatic abscess; pyogenic and amoebic [1,2]. There are various complications associated with hepatic abscesses, of which, rupture of the abscess is the most common [3-5]. Intraperitoneal rupture of liver abscess is a rare but potentially fatal disease, often involving the elderly, who are commonly of poor surgical risk with background of significant medical illness [6,7]. Accurate preoperative diagnosis is difficult and often necessitates exploratory laparotomy for peritonitis [8].

Computed tomography (CT) is an ideal tool for diagnosing hepatic abscesses, and the sensitivity of $\mathrm{CT}$ for detecting hepatic abscesses is as high as 97\% [9]. On CT, an hepatic abscess appears as a single or multiloculated mass with low attenuation [9]. Early diagnosis and prompt therapy are essential to reduce the morbidity and mortality associated with a pyogenic hepatic abscess. The mortality rate is low when the abscess is confined to the liver; however, the mortality rate is increased when the hepatic abscess extends into the chest, peritoneal cavity, or pericardial cavity [10]. Therefore, the early detection of complications associated with hepatic abscesses is important. In hepatic abscess, various complications have been described [11-13], and the rate of complications was reported to be $10.3 \%$ [10]. Reports of complications in pyogenic hepatic abscess are rare, however, and the imaging appearance has been studied in only a small number of patients $[13,14]$. This article presents the $C T$ and clinical findings of our patients with intra-abdominal ruptured liver abscess.

\section{Patients and Methods}

This is aretrospective observational study of patients with intraabdominal ruptured liver abscess presenting to Cho Ray hospital 
Huy et al., Medical Imaging and Radiology 2019,

between 2014 and 2018. The study was approved by the Hospital Ethical Board. All diagnosed cases of ruptured liver abscess based on radiology and laparoscopic investigation were included in the study. Details of demographics, clinical features, computed tomography were recorded. Data will be analyzed using SPSS software.

\section{Clinical parameter}

Demographic and clinical characteristics comprised age, sex, underlying medical conditions (diabetes mellitus, biliary disorders, hemodialysis, liver cirrhosis, malignancy, immunosuppression, cavities from old calcified echinococcus cysts, simple benign liver cysts), symptoms and signs at presentation and origin of the abscess. Patients receiving empiric therapy with antibiotics prior to admission were also recorded.

\section{Liver CT characteristics}

All patients underwent contrast enhanced CT of the liver before laparoscopic drainage of the liver abscess. In some patients, CT studies were also performed during follow-up to assess the size of the abscess cavity, monitor complications. However, we only reviewed the contrast-enhanced $\mathrm{CT}$ images obtained before drainage of the liver abscess, for the purpose of this study.

The CT examinations were performed using Somatom Sensation 64, Siemens, Germany. The scanning parameters varied during the study period and with different scanners: collimation ranged from $1.25 \mathrm{~mm}$ to $7 \mathrm{~mm}$; pitch ranged from 0.75 to 1.5 ; section thickness ranged from $1 \mathrm{~mm}$ to $5 \mathrm{~mm}$. Liver examinations were conducted using $100 \mathrm{ml}$ of intravenous non-ionic iodinated contrast medium (Ultravist, Schering, Berlin, Germany) and dosage was calculated based on the patients' weight and administered viaa power injector at a rate of $3 \mathrm{~mL} / \mathrm{sec}$. Axial sections of 3-5 mm thickness were reconstructed, reported, and archived.

The scans were reviewed by two radiologists who reached agreement between them. The following features were recorded: (a) lobe involvement (unilobar [right or left] or bilobar); (b) number of abscesses (single or multiple); (c) maximal abscess diameter, with the largest abscess measured when there were multiple abscesses; (d) unilocular or multilocular (presence of $\geq 1$-mm-thick septations), multilocular abscess; (e) solid or cystic appearance ( $>50 \%$ of the abscess cavity appears hypodense or liquefied, with an attenuation value of $\leq 20$ $\mathrm{HU}$ ) in most of the sections showing the abscess cavity, cystic abscess; ( $f$ ) gas within the abscess cavity; and (g) spontaneous rupture of the abscess (based on CT and clinical symptoms).

\section{Results \\ Clinical features}

The study group consisted of 32 patients with a median age of $53.3 \pm 15.3$ years (range, $24-85$ years). There were more men than women in the study, with a male-to-female ratio of 1.9:1. Diabetes mellitus was the most common underlying medical condition (25.0\%), followed by bacterial pneumoniae (18.8\%), hypertension (6.3\%), bile duct stones $(3.1 \%)$ showed in Table 1. None of patients had cirrhosis. Most of the patients were suffering from abdominal pain (96.9\%), malaise and anorexia(96.9\%), fever(78.1\%), peritonitis (78.1\%), and other positive clinical signs showed in Table 2.

Table 1. Underlyung diseases of patients with intra-abdominal ruptured liver abscess.

\begin{tabular}{lll}
\hline Underlying diseases & Frequency & Percentage (\%) \\
\hline Hypertension & 2 & 6.3 \\
Diabetes mellitus & 8 & 25.0 \\
Bacterial pneumoniae & 6 & 18.8 \\
Bile duct stones & 1 & 3.1 \\
\hline
\end{tabular}

Table 2. Clinical presentations of intra-abdominal ruptured liver absces.

\begin{tabular}{lll}
\hline Clinical presentations & Frequency & Percentage (\%) \\
\hline Abdominal pain & 31 & 96.9 \\
Malaise and anorexia & 31 & 96.9 \\
Nausea/vomiting & 20 & 62.5 \\
Fever $>38^{\circ} \mathrm{C}$ & 25 & 78.1 \\
Jaundice & 5 & 15.6 \\
Peritonitis & 25 & 78.1 \\
Hepatomegaly & 4 & 12.5 \\
\hline
\end{tabular}

\section{Liver CT characteristics}

The mean time interval between the onset of fever and CT was 8.3 days (range, 1-30 days). The mean size of the liver abscess was $8.4 \mathrm{~cm}$ (range, $4.0-14 \mathrm{~cm}$ ). A single abscess was found in 11 patients, and multiple abscesses were seen in 21 patients. Unilobar involvement was seen in 29 patients, with the right lobe affected more commonly $(68.8 \%, 22$ of 32$)$. The abscesses were completely liquefied in 25 patients and gas in the abscess cavity in 7 patients. Free intraperitoneal fluid was seen in all patients. The liver CT chracteristics of intra-abdominal ruptured liver absces was showed in Tables $\mathbf{3}$ and $\mathbf{4}$. Figures $\mathbf{1}$ and $\mathbf{2}$ are CT-scaned images of the ruptured liver absces.

\section{Discussion}

Liver abscess is an important tropical gastrointestinal disorder $[15,16]$. Liver abscess can be classified into pyogenic and amebic, both having its serious implications, especially when presented late. In developing countries, it forms a major cause for mortality and morbidity $[17,18]$. With the advent of modern radiological modalities, diagnosis of hepatic abscess is possible in early stages resulting in nonsurgical management; however, fraction of patients either due to late presentation or refractory disease presents with ruptured liver abscess thereby increasing the mortality, presents with fatal disease 
Huy et al., Medical Imaging and Radiology 2019,

Table 3. CT chracteristics of intra-abdominal ruptured liver absces.

\begin{tabular}{ll}
\hline CT findings & All patients $(\mathbf{n}=\mathbf{3 2})$ \\
\hline Abscess size $(\mathrm{cm})$ & $8.4(4.0-14)$ \\
\hline No. of abscesses & \\
1 & $11(34.4)$ \\
$>1$ & $21(65.6)$ \\
\hline Lobar involvement & \\
Unilobar & $29(90.6)$ \\
Bilobar & $3(9.4)$ \\
\hline Abscess appearance & \\
Completely liquefied & $25(78.1 \%)$ \\
Gas in the abscess cavity & $7(21.9)$ \\
\hline Peritoneal effusion & $32(100 \%)$ \\
\hline
\end{tabular}

Table 4. Locations of rupture on CT-scaned image.

\begin{tabular}{llllllll}
\hline & \multicolumn{3}{l}{ Right lobe } & & \multicolumn{3}{l}{ Left lobe } \\
\hline $\begin{array}{l}\text { Liver } \\
\text { segments }\end{array}$ & IV & V & VI & VII & VIII & II & III \\
\hline $\begin{array}{l}\mathrm{N} \\
(\%)\end{array}$ & 5 & 8 & 13 & 8 & 8 & 8 & 5 \\
\hline Total & $(15,6)$ & $(25)$ & $(40,6)$ & $(25)$ & $(25)$ & $(25)$ & $(15,6)$ \\
\hline
\end{tabular}

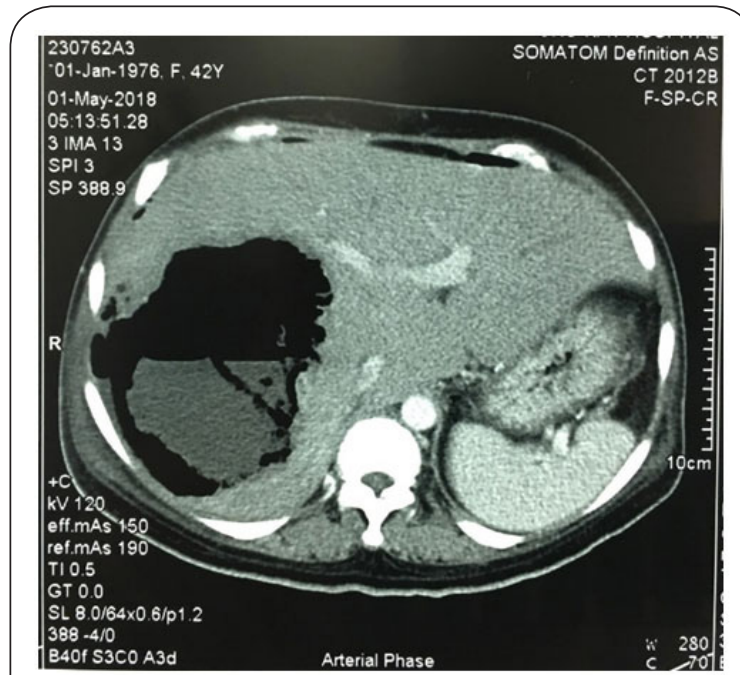

Figure 1. A 42-year-old woman with rupture of a pyogenic hepatic abscess into the peritoneal cavity resulting in peritonitis. The abscess is located in the right hepatic lobe with gas inside.

course, and requires surgical intervention at the earliest $[8,19]$. Intraperitoneal rupture is one of the serious complication of liver abscesses $[\mathbf{5}, \mathbf{1 0}, \mathbf{2 0}, \mathbf{2 1}]$. The frequency of intra periton-ealrupture of an liver abscess varies from $2.5 \%$ to $17 \%$ [22]. Clinically, increasing hepatic tenderness should indicate an impending rupture [22]. Computed tomography may provide important information regarding the extent of intraperitoneal spread of the liver abscess. Dal Mo Yang et al

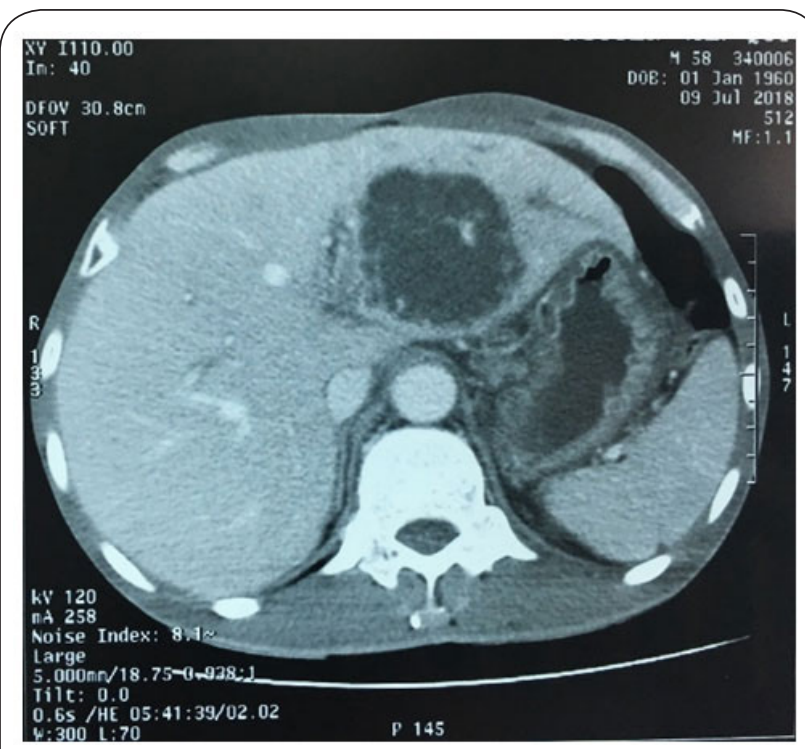

Figure 2. A 62-year-old man rupture of a pyogenic hepatic abscess forming a perihepatic abscess. An enhanced helicalcomputed tomography scan shows a heterogeneously hypodense abscess in the left hepatic lobe.

[23] study 81 patients who had a confirmed pyogenic hepatic abscess, the complication was encountered in 3 patients (3.7\%), and 2 types could be recognized:a loculated perihepatic abscess $(n=2)$ and diffuse peritonitis $(n=1)$. In diffuse peritonitis secondary to rupture of a hepatic abscess, a large amount of ascites and diffuse thickening of the parietal peritoneum could be seen on CT. Although an amebic peritonitis secondary to rupture of a hepatic amebic abscess showed a poor survival rate despite surgical intervention, all the patients with intraperitoneal rupture of the pyogenic hepatic abscess could be treated with percutaneous drainage and antibiotic treatment.

The most common presentation was abdominal pain (96.9\%), malaise and anorexia (96.9\%), fever (78.1\%), peritonitis (78.1\%), nausea/vomiting (62.5\%), jaundice and hepatomegaly (15.6\% and $12.5 \%$, respectively). This results were comparable to study by Hind S. Alsaif with the most common presentation was fever and/or chills, followed by gastrointestinal symptoms (eg, gastrointestinal upset, diarrhea, vomiting, nausea, discomfort, pain), respiratory symptoms(eg, cough, dyspnea, chest distress), andjaundice [24]. The clinical features of ruptured liver absces according to other studies was summarized in the Table 5.

The CT appearance of liver abscess is variable and nonspecific. One or more round or oval low-density lesions 2-1 $6 \mathrm{~cm}$ in diameter may be seen. The margin of the abscess may be smooth or nodular, and one or more internal septations may be present. An enhancing wall is common but not universal. However, the wall may not be apparent if unen- hanced $\mathrm{CT}$ is not performed. Thus, the CT differential diagnosis of amebic liver abscess in the adult includes simple hepatic cyst, infected or hemorrhagic cyst, pyogenic liver abscess, 
Huy et al., Medical Imaging and Radiology 2019,

http://www.hoajonline.com/journals/pdf/2054-1945-7-3.pdf

doi: $10.7243 / 2054-1945-7-3$

Table 5. Presentation symptoms according to other studies.

\begin{tabular}{llll}
\hline Symptoms & $\begin{array}{l}\text { Shrikant Perka } \\
\text { et al (2016) }\end{array}$ & $\begin{array}{l}\text { Alexopoulou } \\
\text { A et al (2010) } \\
\text { [3] }\end{array}$ & $\begin{array}{l}\text { Mukhopadhyay } \\
\text { M et al (2010) } \\
{[\mathbf{4}]}\end{array}$ \\
\hline Pain & $100 \%$ & $75.7 \%$ & $83 \%$ \\
Fever & $86.7 \%$ & $96.7 \%$ & $80 \%$ \\
Vomiting & $43.3 \%$ & -- & -- \\
Cough/pleurisy & $30 \%$ & -- & $26.4 \%$ \\
Diarrhea & $53.3 \%$ & -- & -- \\
Jaundice & -- & $12.1 \%$ & -- \\
\hline
\end{tabular}

echinococcal cyst, hematoma, biloma, cystic or necrotic hepatic metastasis, undifferentiated embryonal sar- coma, and biliary cystadenoma. In the few cases in which a rim of edema is seen peripheral to the lesion, diagnostic consideration may be limited to inflammatory conditions [26]. A feature of amebic liver abscess that may aid in distinguishing it from other focal hepatic lesions is its tendency to extend beyond the surface of the liver.

Our results of liver $\mathrm{CT}$ characteristics were comparable to other studies. Alsaif HS et al showed that the median time interval between theonset of fever and CT was 3 days (range, 1-24 days). The median size of the liverabscess was $7 \mathrm{~cm}$ (range, $1.7-14 \mathrm{~cm}$ ). Asingle abscess was found in 95 patients, and multiple abscesses were seen in 36 patients. Unilobar involvement wasseen in 100 patients, with the right lobeaffected more commonly $(55.0 \%$, 72 of 131$)$. The abscesses were predominantly solidand masslike in 67 patients and cystic in 64 patients. Multilocular appearance of the abscesses was present in 115 patients (87.8\%). Thrombophlebitis was present in 30 patients; pylephlebitis, in three; gas in the abscess cavity, in 17; and pneumobilia, in six. Three patients had both gas in the abscess cavity and pneumobilia [24]. Sutdy by Alexopoulou A et al, the majority (69.7\%) of liver abscess involved the right lobe, they were $5-9 \mathrm{~cm}$ in size $(63.6 \%)$ and solitary (75.7\%). Multiple abscesses were observed in $24.2 \%$ of patients. The presence of elevated hemidiaphragm (42.4\%), pleural effusion (18.2\%) and basilar infiltrate (6\%) in chest radiography was also noted. Liver abcess was accompanied by pylephlebitis in 1 patient. Gas forming were observed in 4 patients $(12.1 \%)$ and loculated subcollections in the abscess in $3(9 \%)$ [3]. A single abscess was found in $54(81.8 \%)$ patients, and multiple abscesses were seen in 12 (18.2\%) patients in the study ofChang $Z$ et al [27]. Among the patients with multiple abscesses, the average number of lesions per patient was 2.5 0.67. Unilobar involvement was seen in $54(81.8 \%)$ patients, and multilocular abscess was present in $50(75.8 \%)$ patients. The abscesses were predominantly solid in $38(57.6 \%)$ patients and cystic in $28(42.4 \%)$ patients. Thrombophlebitis was present in $9(13.6 \%)$ patients, and gas in the abscess cavity was present in 11 patients (16.7\%). There were 4 (6.1\%) patients with liver abscess who experienced a spontaneous rupture of the abscess [27].
A definitive diagnosis of liver abscess requires imaging, with both sonography and CT being useful. Sonography is operator-dependent and the operator may have difficulty picking out a small, solitary abscess. Its sensitivity is around 79\%, compared with $98 \%$ for CT [28], but emergency bedside sonography may be very useful in making a rapid diagnosis. Kim et al. suggested certain CT characteristics suggestive of a Klebsiellaabscess, such as a hairball sign or air-fluid level [29]. However, while such imaging distinctions may be sought, culture and sensitivity results are the key to choosing the appropriate antibiotics.

The advancement in radiologic techniques has been credited with the improvement in mortality rates. Ultrasonography and $\mathrm{CT}$ evaluation with contrast remain the radiologic modalities of choice in screening procedures and also can be used as techniques for guiding percutaneous aspiration and drainage. With advancement in multidetector CT scan technology, image quality has improved dramatically, allowing for improved detection. Besides, gallium and technetium radionucleotides can be used in diagnosis.

\section{Conclusions}

A ruptured hepatic abscess is more life-threatening than an unruptured one. A rapid and accurate diagnosis and prompt surgical intervention are essential. Most of the cases had an acute presentation and the right lobe is commonly affected. Abdominal pain was the most common symptom. Computed tomography is an ideal tool for diagnosing hepatic abscesses and its complications.

\section{Competing interests}

The authors declare that they have no competing interests.

Authors' contributions

\begin{tabular}{|l|c|c|c|c|}
\hline Authors' contributions & HQH & LCT & LQM & NQV \\
\hline Research concept and design & $\checkmark$ & $\checkmark$ & $\checkmark$ & $\checkmark$ \\
\hline Collection and/or assembly of data & $\checkmark$ & -- & $\checkmark$ & -- \\
\hline Data analysis and interpretation & $\checkmark$ & $\checkmark$ & -- & -- \\
\hline Writing the article & $\checkmark$ & -- & -- & -- \\
\hline Critical revision of the article & $\checkmark$ & $\checkmark$ & -- & -- \\
\hline Final approval of article & $\checkmark$ & $\checkmark$ & $\checkmark$ & $\checkmark$ \\
\hline Statistical analysis & $\checkmark$ & $\checkmark$ & -- & -- \\
\hline
\end{tabular}

\section{Acknowledgments}

The authors are grateful to physicians, administrative staff at Cho Ray Hospitals for allowing us to undertake this research.

\section{Publication history}

Senior Editor: Domenico Rubello, Santa Maria della Misericordia Hospital, Italy.

Received: 26-Apr-2019 Final Revised: 05-Jun-2019

Accepted: 07-Jun-2019 Published: 14-Jun-2019 
Huy et al., Medical Imaging and Radiology 2019,

\section{References}

1. Akhondi $\mathrm{H}$ and Sabih DE. Liver Abscess, in StatPearls. Treasure Island (FL). 2019.

2. Chia DWJ, Kuan WS, Ho WH, Sim TB and Chua MT. Early predictors for the diagnosis of liver abscess in the emergency department. Intern Emerg Med. 2019. | Article I PubMed

3. Alexopoulou A, Dimopoulou H, Soultati A, Panetsos G, and Dourakis SP. Factors related to complications and mortality in pyogenic liver abscesses. Annals of Gastroenterology. 2010; 23:296-301.

4. Mukhopadhyay M, SahaAK, Sarkar A and Mukherjee S. Amoebic liver abscess: presentation and complications. Indian J Surg. 2010; 72:37-41.

5. Satish KR, Sathyanarayana BA, Madhu SL, Nataraj NR, Amit GM and Hemanth V. A study of predictors for identification of risk of complications in patients with liver abscess. Trop Gastroenterol. 2015; 36:96-100. I PubMed

6. Elechi EN and Etawo SU. Management of intraperitoneal rupture of amoebic liver abscess: a 6-year experience with 11 cases in Port Harcourt, Nigeria. Trop Doct. 1991; 21:43-4.

7. SardaAK, Bal S, Sharma AK and Kapur MM. Intraperitoneal rupture of amoebic liver abscess. Br J Surg. 1989; 76:202-3.

8. Memon AS, Siddiqui FG, Memon HA and Ali SA. Management of ruptured amoebic liver abscess: 22-years experience. J Ayub Med Coll Abbottabad. 2010; 22:96-9. | PubMed

9. Halvorsen RA, Korobkin M, Foster WL, Silverman PM and Thompson WM The variable CT appearance of hepatic abscesses. AJR Am J Roentgenol. 1984; 142:941-6. | Article I PubMed

10. Munoz LE, Botello MA, Carrillo O and Martinez AM. Early detection of complications in amebic liver abscess. Arch Med Res. 1992; 23:251-3. I PubMed

11. Mondragon-Sanchez R, Cortes-Espinoza T, Sanchez-Cisneros R, ParraSilva $\mathrm{H}$ and Hurtado-Andrade $\mathrm{H}$. Rupture of an amebic liver abscess into the pericardium. Presentation of a case and review of current management. Hepatogastroenterology. 1994; 41:585-8.

12. Mowji PJ, Cohen AJ, Potkin B and Viltuznik J. Amebic liver abscess with hepatoduodenal fistula. Am J Gastroenterol. 1987; 82:558-9. | PubMed

13. Tandon N, Karak PK, Mukhopadhyay S and Kumar V. Amoebic liver abscess: rupture into retroperitoneum. Gastrointest Radiol. 1991; 16:240-2.

14. Yamada S, Maruo H, Mori $\mathrm{K}$ and Kosaka A. [An unusual case of pyogenic hepatic abscess rupturing into the pericardial cavity]. Nihon Kyobu Geka Gakkai Zasshi. 1996; 44:2072-5. | PubMed

15. Cook GC. Gastroenterological emergencies in the tropics. Baillieres Clin Gastroenterol. 1991; 5:861-86.

16. Reeder MM. Tropical diseases of the liver and bile ducts. Semin Roentgenol. 1975; 10:229-43. I Article I PubMed

17. Blessmann J, Van Linh P, Nu PA, Thi HD, Muller-Myhsok B, Buss $\mathrm{H}$ and Tannich $\mathrm{E}$. Epidemiology of amebiasis in a region of high incidence of amebic liver abscess in central Vietnam. Am J Trop Med Hyg. 2002; 66:578-83. | Article | PubMed

18. Kannathasan S, Murugananthan A, Kumanan T, de Silva NR, Rajeshkannan N, Haque R and Iddawela D. Epidemiology and factors associated with amoebic liver abscess in northern Sri Lanka. BMC Public Health. 2018; 18:118. | Article I PubMed Abstract | PubMed FullText

19. Short M and Desai AP. Laparoscopy and transdiaphragmatic thoracoscopy in management of ruptured amebic liver abscess. J Laparoendosc Adv Surg Tech A. 2008; 18:473-6.

20. Adams EB and MacLeod IN. Invasive amebiasis. II. Amebic liver abscess and its complications. Medicine (Baltimore). 1977; 56:325-34. | Article | PubMed

21. Jolobe OM. Intrahepatic expansion of amebic liver abscess can also generate life-threatening complications. South Med J. 2010; 103:118990.

22. Eggleston FC, Handa AK and Verghese M. Amebic peritonitis secondary to amebic liver abscess. Surgery. 1982; 91:46-8. | PubMed

23. Yang DM, Kim HN, Kang JH, Seo TS, Park CH and Kim HS. Complications of pyogenic hepatic abscess: computed tomography and clinical features. J Comput Assist Tomogr. 2004; 28:311-7.

24. Alsaif HS, Venkatesh SK, Chan DS and Archuleta S. CT appearance of pyogenic liver abscesses caused by Klebsiella pneumoniae. Radiology. 2011; 260:129-38.

25. Perka S, Khajanchi M, Pothare A and Nandu V. Audit of patients with ruptured amoebic liver abscess and outcome of surgical versus nonsurgical treatment. International Surgery Journal. 2016; 3:2163-2166.

26. Gabata T, Kadoya M, Matsui O, Kobayashi T, Kawamori Y, Sanada J, Terayama N and Kobayashi S. Dynamic CT of hepatic abscesses: significance of transient segmental enhancement. AJR Am J Roentgenol. 2001; 176:675-9.

27. Chang Z, Zheng J, Ma Y and Liu Z. Analysis of clinical and CT characteristics of patients with Klebsiella pneumoniae liver abscesses: an insight into risk factors of metastatic infection. Int J Infect Dis. 2015; 33:50-4.

28. Pearl R, Pancu D and Legome E. Hepatic abscess. J Emerg Med. 2005; 28:337-9.

29. Kim SB, Je BK, Lee KY, Lee SH, Chung HH and Cha SH. Computed tomographic differences of pyogenic liver abscesses caused by Klebsiella pneumoniae and non-Klebsiella pneumoniae. J Comput Assist Tomogr. 2007; 31:59-65.

\section{Citation:}

Huy HQ, Tri LC, Minh LQ and Vinh NQ.

Intra-abdominal Ruptured Liver Abscess: Computed Tomography and Clinical Features. Med Imaging Radiol. 2019; 7:3. http://dx.doi.org/10.7243/2054-1945-7-3 